\title{
Pre-design inspection of the long-term operation lock
}

\author{
Lyudmila Frishter $^{1, *}$ and Alexander Isaikin $^{2}$ \\ ${ }^{1}$ Moscow State University of Civil Engineering, Yaroslavskoe shosse, 26, Moscow, 129337, Russia \\ ${ }^{2}$ Inzhstrojjservis, St. Staroslobodskaya, 3, office 7, Moscow, 107113, Russia
}

\begin{abstract}
For hydraulic structures of long-term operation, assessments of operating life, limit states and safety of structures are required. The design of reconstruction, restoration of functional parameters of structures is preceded by pre-design inspections of the structure. The relevance of predesign inspections is the need to assess the characteristics of technical and operating state of the structure, to describe reasons for deviations from design parameters of operation, to obtain recommendations to justify the design of reconstruction, restoration or repair of structures. This article presents the results of a pre-design inspection of a high-pressure lock on the Ufa River. An analysis of the complex of effects on the stress-strain state of the structure, static calculation of the lock chamber wall is carried out considering design changes during the operation period - installation of additional buttresses, vibrodynamic inspection and calculation. The obtained calculation results are compared with data of instrumentation equipment. The purpose of the inspection is to obtain a preliminary design assessment of technical state of the hydraulic structure - lock, including an assessment of the possibility of further operation. The practical significance of the paper is determined by the fact that the results obtained can serve as baseline data for a design of reconstruction, restoration of a hydraulic structure and recommendations for ensuring its long-term safe operation.
\end{abstract}

\section{$1 \quad$ Introduction}

The safety of hydraulic structures in the long term of operation necessitates the repair, reconstruction, restoration of essential structures. The relevance of pre-design inspections of hydraulic structures is the need to assess the characteristics of the technical and operating state of the structure, to describe the reasons for deviations from the design parameters of operation, to obtain recommendations to justify the design of reconstruction or restoration of structures.

The relevance of the topic of study of the state of hydraulic structures of a long-term service life is reflected in many papers [1-11]. The main focus of the papers is the assessment of the technical state and level of safety, durability of hydraulic structures with a long-term service life [1-4]. In many papers [1-11] modern technologies and new materials for the repair and reconstruction of hydraulic structures are considered. In the

\footnotetext{
*Corresponding author: 1frishter@mail.ru
} 
paper [1-4] the requirements for the technology of reconstruction of structures, which allow not to suspend the full operation of hydraulic structures, are noted.

In paper [1] points out the need for a systematic approach to assessing the performance of hydraulic structures of a long service life and attracting organizational resources to develop unified common criteria for assessing the state of structures, considering their uniqueness, and not simply describing the operation of the structure and the state of the hydraulic facility. In paper [1] it is noted that "the use of general principles for the assignment of limit values does not preclude a thorough analysis of the results of actual observations and measurements". This article provides a comprehensive assessment of the effects on the stress-strain state of the structure - the lock.

The purpose of the inspection is to obtain a preliminary design assessment of the technical state of the hydraulic structure - the lock, including an assessment of the possibility of further operation. The practical significance of the paper is determined by the fact that the results obtained can serve as baseline data for a design of reconstruction, restoration of a hydraulic structure - the lock - and recommendations for ensuring its longterm safe operation.

\section{Problems statement for the lock inspection and their solutions}

\subsection{Description of the facility. History of operation of the lock, features of the lock. Problems statement}

The high-pressure lock with a pressure of $39 \mathrm{~m}$ has been in operation for more than 60 years, is located on the Ufa River upstream of the city of Ufa, and is part of the Pavlovsky hydroelectric complex. The navigation lock is single-stage, single line, of mine type, made of reinforced concrete. The structures of the lock include the upper head, the lower head, the lock chamber, the approach channels, and the pawls of the upper and lower pools.

The functional task of the lock is to maintain the water level in the upstream pool, passing rafts and vessels, passing the peak part of a catastrophic flood with a frequency of $1 \%$. The normal headwater elevation has a mark of $140.0 \mathrm{~m}$, the minimum and maximum navigation levels of the downstream pool are $-107.1 \mathrm{~m}, 113 \mathrm{~m}$, respectively. The base of the lock chamber has a mark of $95 \mathrm{~m}$, the mark of the top of the expansion joint is $-100.14 \mathrm{~m}$.

The lock chamber has overall dimensions of $120^{\times} 12.0 \mathrm{~m}^{2}$, four sections of $24.3 \mathrm{~m}$ each, which are separated from the adjacent heads and between each other by contraction joints. Chamber sections No. 2, 3, 4 have split bottoms. The annicut adjoins the lock at the left, which is combined with the HPP building, and an earthen channel (right bank) dam adjoins the lock on the right.

During the operation of the lock in 1998 to increase the rigidity of section No. 4, the buttresses were installed.

At the Pavlovsky Lock the instrumentation equipment is installed, the instrumental control service runs.

By the leading marks of section 4 of the right wall of the lock chamber from 1958 to 1998 a displacement was recorded, which according to the measurements made a residual deviation of $55.3 \mathrm{~mm}$, which corresponds to an average deviation rate of $\approx 1.4 \mathrm{~mm} / \mathrm{g}$.

By the leading marks of sections 3 and 4 of the right wall of the lock chamber, after installing the buttresses in 1998, the sections were shifted towards the chamber axis, with the largest deviations observed during the inter-navigation period. 
Deviations of the last 10 years are: for section 4 by mark m6b $-5.4 \mathrm{~mm} / \mathrm{g}$, by slitmetering device No. 13 (Chief of General Staff - section 4) $-1.7 \mathrm{~mm} / \mathrm{g}$, for section 3 by mark $\mathrm{m} 5 \mathrm{a}-1.7 \mathrm{~mm} / \mathrm{g}$.

Determining the causes of displacements for the right wall of the lock of section 4 with a split bottom, which has the greatest displacements, necessitates the analysis of the stressstrain state (SSS) of the chamber wall during static, dynamic effects.

The end wall of the hydroelectric power plant, which is adjacent to the lock, affects the operation of the lock chamber. Vibrodynamic effects on the wall arise due to the permanent operation of the HPP hydroelectric installations.

\subsection{Static calculation of the lock chamber wall}

The purpose of the static calculation is to determine the most hazardous areas on the front side of the chamber wall according to the stress-strain state, considering the different operating conditions of the lock and changes in the rigidity of the chamber wall when installing additional buttresses.

Initial data received from the customer: cross-sectional view diagrams of the lock sections, plan and cross-sectional view of the lock, data on the displacements of the chamber wall in section 3 and 4, data on the subsidences of the lock.

Static calculation of the lock chamber wall is carried out in accordance with the regulatory requirements [12-16] for operational case 2 with a minimum level of filling the chamber with water for two cases: with and without buttresses, as it was designed in 1998, as well as for a repair case in the absence of water in the lock chamber.

The calculation is carried out for the right wall of the lock of section 4 (figure 1), since the greatest displacements are observed for this wall. The ANSYS software package is used, the finite-element model of the cutting is made of PLANE182 elements. The beginning of the rectangular coordinate system is at the lower point of the base of the expansion joint, axis $O X$ is directed to the right, axis $O Y$ is directed up.

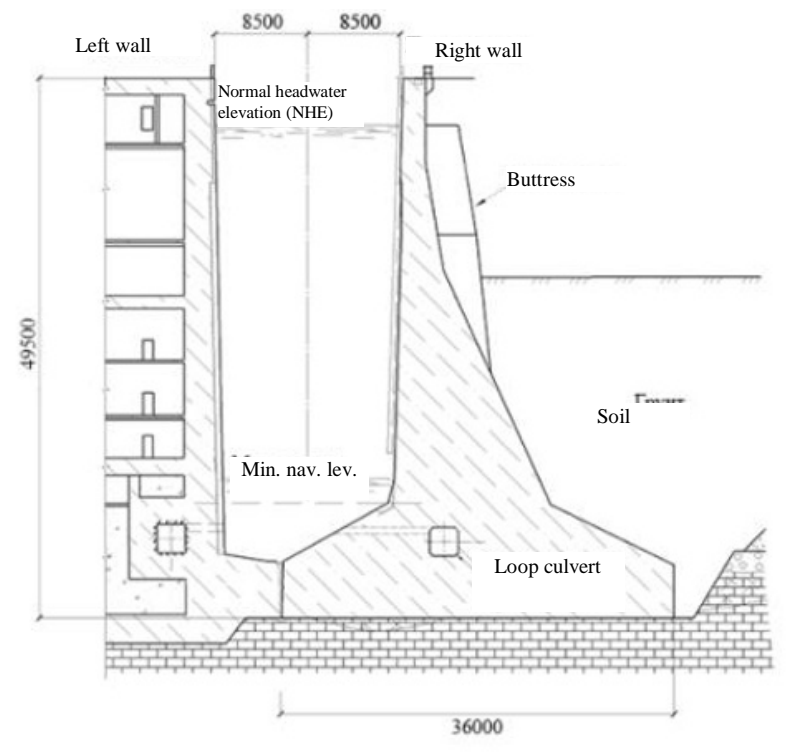

Fig. 1. Cross sectional view of section 4 of the lock chamber 
For operational case 2, it is considered [16]: load from the water in the chamber at the minimum navigation level, pressure of the backfill soil, considering the suspended state at the highest level of downstream pool, self-weight of the wall, breast stay of water from the downstream pool and weighing pressure on the bottom of the wall base. For the repair case, the complete emptying of the chamber is considered.

The material of the lock wall is concrete B30. According to the recommendations [12, 16], it is adopted: modulus of elasticity $-37 \mathrm{MPa}$, Poisson's ratio -0.15 .

The lock is located on a limestone base, reinforced by a filtration curtain, which makes it possible to accept hinged immovable supports for calculation at the base of the lock.

Backfill soil is construction sand with the characteristics: the specific gravity of particles $-2,650 \mathrm{~kg} / \mathrm{m}^{3}$; the specific gravity in the suspended state $-2,000 \mathrm{~kg} / \mathrm{m}^{3}$, porosity ratio - 0.65; Poisson's ratio - 0.3. Soil pressure is calculated according to the recommendations $[12,13]$.

The calculation does not consider: temperature effects corresponding to changes in average monthly ambient temperatures for the average temperature conditions of the year [17], pulsating loads of water, and the load from the impact of ships. Vibrodynamic loads caused by the operation of hydroelectric installations adjacent to the hydraulic plant lock are considered separately.

\subsection{The calculation results for section 4 of the chamber wall of the lock, considering the change in stiffness in operational and repair cases 2 . Comparison with experimental data}

For operational case 2, the largest compressive friction stresses [18]: $\tau_{\mathrm{xy}}=-1.03 \mathrm{MPa}$ (with a buttress), $\tau_{x y}=-0.9 \mathrm{MPa}$ (without a buttress), are observed in the area of conjugation of the wall and the left console of the bottom. The largest tensile friction stresses: $\tau_{x y}=0.42 \mathrm{MPa}$ (with a buttress), $\tau_{x y}=0.37 \mathrm{MPa}$ (without a buttress), are observed in the corner areas of the drainage gallery, the corner area of the chamber bottom.

For operational case 2, the largest compressive stresses: $\sigma_{\mathrm{x}}=-1.0 \mathrm{MPa}$ (with a buttress), $\sigma_{\mathrm{x}}=-0.735 \mathrm{MPa}$ (without a buttress), are observed in the area of stress concentration in the area of conjugation of the wall and the left console of the bottom. The largest tensile stresses: $\sigma_{\mathrm{x}}=0.45 \mathrm{MPa}$ (with a buttress), $\sigma_{\mathrm{x}}=0.29 \mathrm{MPa}$ (without a buttress), are observed in the area of the drainage gallery

The presence of surcharge (buttresses) increases the area of compressive stresses $\sigma_{\mathrm{x}}$ and improves for $\sigma_{\mathrm{x}}$ the work of the area of expansion joint in the bottom of the chamber, the area of the drainage gallery and the corner area of the rear console of the bottom.

For operational case 2 , the largest compressive stresses: $\sigma_{\mathrm{y}}=-1.83 \mathrm{MPa}$ (with a buttress), $\sigma_{y}=-1.45 \mathrm{MPa}$ (without a buttress), are observed in the area of conjugation of the wall and the left console of the bottom. The largest tensile stresses $\sigma_{\mathrm{y}}$ are observed in the corner area of the rear console of the bottom of the gallery.

Buttresses are an additional surcharge which increases the area of compressive stress, but at the same time improves the work of the expansion joint in the bottom of the chamber, the area of the drainage gallery and the corner area of the rear console of the bottom.

The stress values in repair and operational cases 2 of the chamber with the buttress practically coincide. 
The results of the static calculation of the wall of section 4 of the chamber [18] show that in the second operational case the largest total displacements are achieved in the upper part of the wall in the direction of the lock axis (with buttresses) and equal to $1.87 \mathrm{~mm}$. For the option without buttresses, the total displacements in this area are $2.3 \mathrm{~mm}$. The total displacement is mainly determined by the horizontal component in the direction of the lock axis.

In operational case 2, the largest horizontal displacements are achieved in the upper wall area in the direction of the lock axis and are equal to $\mathrm{u}_{\mathrm{x}}=-1.7 \mathrm{~mm}$ (with buttresses). The obtained calculation data are consistent with the data of instrumental control over the past 10 years in this area of the wall, which constitute $u_{x}=$ $-1.70 \mathrm{~mm} / \mathrm{g}$.

In operational case 2 , on the upper levels of the wall, the downward movements are: $\mathrm{u}_{\mathrm{y}}$ $=-0.78 \mathrm{~mm}$ (with a buttress), $\mathrm{u}_{\mathrm{y}}=-0.7 \mathrm{~mm}$ (without a buttress). In the upper levels of the wall in the repair and operational cases, the values of displacements differ slightly, i.e. the presence of water with a minimum navigation level has little effect on vertical movements of the top of the wall.

The largest total displacements of the wall with the buttress, as a whole, for operational and repair cases 2 almost coincide.

Determining the values of displacements and stresses of the wall of the lock section, their comparison with the data of instrumental control allows us to evaluate the safety of the lock chamber.

\subsection{Experimental studies of vibrodynamic oscillations}

The purpose of vibrodynamic studies (monitoring) is to identify the frequencies causing the resonance of natural and forced oscillations and a sharp increase in the amplitude of oscillations [19, 20].

Vibrodynamic oscillations of the upper walls of the lock chamber from the effects of hydroelectric installations of the neighboring HPP for the repair case of the lock operation are being studied. For oscillation measurements, broadband oscillation pickups (velocimeters) SP 400 are used. Oscillation pickups (seismometers) consist of three single component molecular and electronic sensors mounted in a common tank. The sensor axes are oriented in three mutually perpendicular directions (two horizontal and a vertical). Oscillation measurements are carried out on both walls of the lock at 18 points. Figure 2 shows a diagram of the lock fragment with an indication of the installation points for the oscillation pickups.

The operation of the HPP hydroelectric installations causes the oscillations of the lock walls, has a background character. The resulting oscillation amplitudes of the top of the lock walls due to the operation of hydroelectric installations are insignificant, reaching 3 microns.

The amplitudes of the acceleration points of the lock wall are small and do not exceed $0.01 \mathrm{~m} / \mathrm{sec}^{2}$. The prevailing oscillation frequency is $10.3 \mathrm{~Hz}$ and is mainly determined by the rotational speed of the turbogenerators at $618 \mathrm{rpm}$.

Some records have a peak at a frequency of about $0.07 \mathrm{~Hz}$, which is defined as instrumental error. In addition to these two frequencies, there are other peaks in the spectra, which reflect the natural frequencies of the lock walls and individual structural elements adjacent to the lock (dam, swing bridge, upper and lower head closures, etc.). 
In the performed study, forced oscillations from the operation of the HPP turbine units and a number of natural oscillations of the lock construction structures, including the walls of its chamber, were recorded.

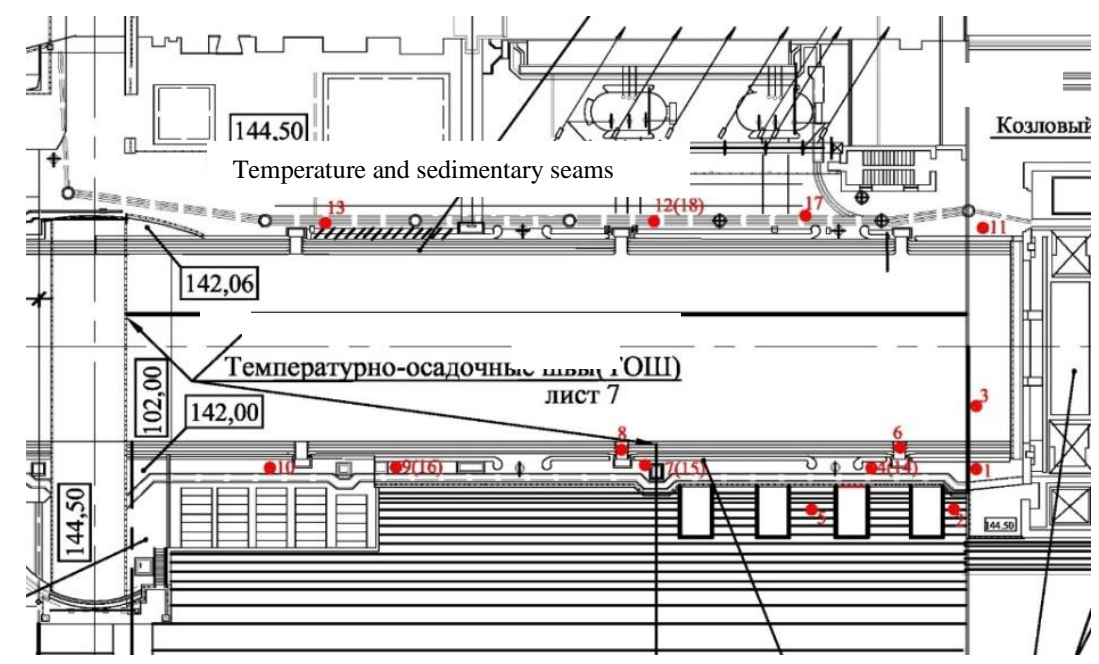

Fig.2. Diagram of the lock chamber with indication of the installation ${ }_{1} \quad f$ the oscillation pickups. Figures without brackets - the 1st measurement day (operation of two units); figures in brackets - the 2nd day (operation of one HPP unit).

\subsection{Vibrodynamic monitoring data and dynamic calculation of the lock wall}

Vibrodynamic monitoring data is used to estimate the dynamic calculation and compare the results of the calculation and monitoring $[19,20]$.

The calculation is carried out for the right wall of section 4 of the lock using the ANSYS software package. According to the vibrodynamic monitoring data, the maximum acceleration of the upper wall of the chamber of the lock of section No. 4 is $0.01 \mathrm{~m} / \mathrm{sec}^{2}$. At the base of the lock wall in the area of junction to the bottom of the chamber, the acceleration is zero. Force $\mathrm{F}=$ ma effects the wall, where $\mathrm{m}$ is the mass of elements into which the wall of the chamber is broken, considering their rigidity.

Considering the maximum accelerations of the points of the upper wall of section No. 4, the values of displacements obtained for the repair case are insignificant, which is consistent with the monitoring data and the static calculation from the complex of effects.

The stress-strain state of the lock wall for the repair case of operation, obtained considering the maximum accelerations of the points of the upper wall according to vibrodynamic monitoring, characterizes the "own" VAT arising in the weighing wall under operating loads, therefore, it is not much different from the results of static calculation.

\section{Results}

The largest total displacements of the wall of the lock chamber obtained by calculation are observed in the upper area of the wall inside the lock and are $1.66 \mathrm{~mm}$, which is consistent with the data of instrumental control of movements in the area of the chamber wall of section 4 . The greatest deviation in the last 10 years 
for the wall of section 4 of the lock chamber by the slit-metering device is 1.7 $\mathrm{mm} / \mathrm{g}$. The lock buttresses are an additional surcharge which increases the area of compressive stress, but at the same time improves the work of the expansion joint in the bottom of the chamber, the area of the drainage gallery and the corner area of the rear console of the bottom. The largest compressive stresses are observed in the area of stress concentration in the area of conjugation of the wall and the left console of the bottom.

The obtained data of field measurements of oscillations of the lock walls from the effects of unbalanced masses of the HPP hydroelectric installations show the values of maximum displacement amplitudes not exceeding 4 microns, which is 4 orders of magnitude less than permissible values. At the same time, with working vibrodynamic loads from filling and emptying the lock chamber with water, additional studies are needed, for which the lock inspection program considered in the article can be used when vibrodynamic loads are applied.

\section{Discussion}

Displacement from vibrodynamic effects of section 4 wall without considering the filling of the lock chamber with water is insignificant, which confirms the consistency of the data from vibrodynamic studies, instrumentation equipment, the results of the static calculation and the calculation of VAT considering the maximum accelerations of the points of the upper wall of the lock chamber. Thus, dynamic monitoring can be considered as an unambiguous tool-criterion, which allows to speak about the safe operation of the structure. The advantages of dynamic monitoring of a structure are its cost-effectiveness, the ability to prevent irregularities in the operation of the structure, justify the need for major repairs and the possibility of permanent monitoring of the safe operation of the structure.

\section{Conclusions}

Vibrodynamic studies and static calculations of the lock chamber show that for the repair period (without filling with water) its further operation in this mode is safe.

\section{References}

1. G. E. Shestov, I. V. Vlasova and G. V. Melnik, Hydrotech. 4, pp. 30-36 (2013)

2. V. V. Kropivnitsky, Hydrotech. 3(52), (2018)

3. National Committee of Uzbekistan on large dams. Modern methods and technologies in the field of safety of hydraulic structures. 137 p., www.unece.org (2015)

4. O. M. Shchursky, Hydrotech. 1(34), pp. 8-11 (2014)

5. K. P. Morgunov and M. V. Krasnikova, Vestnik Gosudarstvennogo universiteta morskogo i rechnogo flota imeni admirala S. O. Makarova 4 (38), pp. 74-85 (2016)

6. R. V. Kozlov, V. Li and K. P. Morgunov, Vestnik Gosudarstvennogo universiteta morskogo i rechnogo flota imeni admirala S. O. Makarova 9 (1), pp. 95-110 (2017)

7. A. M. Gapeev, K. P. Morgunov and A. V. Podreshetnikova, Vestnik Gosudarstvennogo universiteta morskogo i rechnogo flota imeni admirala S. O. Makarova 9 (5), pp. 984 992 (2017) 
8. E. V. Maksimenko and S. N. Levachev, Vestnik MGSU 4, pp. 324-329 (2010)

9. T. K. Ksenofontova, A. G. Zhuravleva, Thunzyan Suy, Envir. Engin., 5, pp. 19-25 (2016)

10. S. N. Levachev and T. S. Fedorova, Vestnik MGSU, 8, pp. 137-149 (2013)

11. E. V. Maksimenko and S. N. Levachev, Vestnik MGSU, 4, pp. 337-338 (2010)

12. SP 101.13330.2012. Retaining walls, navigation locks, fish passing and fish protection facilities (The updated edition SNiP 2.06.07-87)

13. Manual for the design of navigation locks. SP 101.13330.2012. Retaining walls, navigation locks, fish passing and fish protection facilities (The updated edition SNiP 2.06.07-87)

14. SP 58.13330.2012. Hydraulic Structures. Basic statements (The updated edition. SNiP 33-01-2003)

15. Recommendations for the survey of hydraulic structures to assess their safety (OAO "VNIIG im. B. E. Vedeneeva", 2000)

16. SP 20.13330.2011 Loads and impacts (The updated edition SNiP 2.01.07-85*)

17. G. L. Hesin, G. S. Vardanyan, A. S. Isaykin, V. N. Savost'yanov, L. Y. Frishter and O. A. Kogodovsky, Hydr. Engin. 8, pp. 20-26 (1988)

18. L. Frishter, P. Ivanov, Proc. Engin. 165, pp. 1035-1038 (2016)

19. G. E. Shablinsky, A. S. Isaykin, D. A. Zubkov et al. Earthquake-proof constr., Saf. of struct. 6 (2005)

20. G. E. Shablinsky and D. A. Zubkov, The field and modeling research of dynamic phenomena in structures of power and civilian facilities. MGSU, 484 p. (2012) 